\title{
Effect of Stress on Central Serous Chorioretinopathy \& Correlation with type of leak on FFA
}

\author{
Sonya Puri ${ }^{1}$, Poninder Kumar ${ }^{2}$, Abhinav Singh ${ }^{3}$, Nidhi Kalra ${ }^{4}$ \\ ${ }^{1}$ Associate Professor, Base Hospital \& ACMS, Delhi Cantt \\ ${ }^{2}$ Professor\& HOD, Base Hospital \&ACMS, Delhi Cantt \\ ${ }^{3}$ Resident, Base Hospital \&ACMS, Delhi Cantt \\ ${ }^{4}$ Assistant Professor, Base Hospital \&ACMS, Delhi Cantt
}

\begin{abstract}
:
Introduction:Central Serous Chorioretinopathy (CSCR) is an idiopathic disorder with neurosensory detachment primarily affecting the macula.

Aim:The aim of this study was to evaluate the stressful events of life within 1 year preceding onset of CSCR and study the correlation with the type of leak.

Materials and Methods:A prospective study was done on 30 patients of CSCR in a tertiary care centre. Demographic data and history were noted, a comprehensive ophthalmic examination was done.All cases underwent OCT \& fundusfluorescein angiography (FFA). They were given a Social Readjustment Rating Score (SRRS) based on life change unitsin the past one year based on a questionnaire. 30 patients from normal population formed a control group.

Results: 93.3\% were males, mean age was 38 yrs. The mean SRRS was 136.73 in the CSCR group compared to 100.5 in the control group. $40 \%$ patients in the CSCR group had scores above 150 compared to $30 \%$ in the control group. 50\% of the patients with multifocal leak had SRRS between 150- 299 compared to $36.36 \%$ among patients with single leak.

Conclusion:Psychological stress plays a significant role in triggering or exacerbating CSCR. Relaxation therapies \& stress management programmes may help in preventing recurrences.

Keywords: Central Serous Chorioretinopathy (CSCR), Holmes Rahe Scale, Social Readjustment Rating Score (SRRS), Fundus fluorescein angiography (FFA).
\end{abstract}

\section{Introduction}

CentralSerous Chorioretinopathy (CSCR) is a disorder characterized by serous retinal detachment and/or retinal pigment epithelial (RPE) detachment in the macula. There is exudation from parafoveal or choroidal capillaries causing oedemalimited to the macula. CSCR is the fourth most common retinopathy after ARMD, diabetic retinopathy and retinal vein occlusions. ${ }^{[1]}$ The term Central Serous Chorioretinopathy was first used in 1967 by Gass. ${ }^{[2]}$ It is a multifactorial disease with complex pathology. It occurs commonly in young adult males ${ }^{[3]}$ with type A personality. ${ }^{[4]}$ It may be associated with corticosteroid use, ${ }^{[5-9]}$ and obstructive sleep apnae..$^{[10,11]}$

Patients usually present with blurred vision, metamorphopsia, micropsia or a relative central scotoma. ${ }^{[12,13]}$

CSCR has been associated with severe psychosocial stressors. ${ }^{[14,15]}$

Thomas Holmes and Richard Rahe in 1967 designed Social Readjustment Rating Score based on 43 life events to study if stress contributes to an illness. ${ }^{[16]}$ Rather than taking an unstructured history they thought it is better to have a list of commonly involved stressors which ranged from death of spouse to change in sleep pattern. Each event called a Life Change Unit has different points allocated to it.(Table 1). The scores are totaled up for the events that have taken place in the last one year. If an event has occurred twice the score for that event is added twice.

A score of less than 150 points implies a relatively low amount of susceptibility to stress-induced health breakdown.150 -299 points indicates about a 50\% chance of a major health breakdown. Scores above 300 points increase the odds to about $80 \%$.

\section{Materials \& Methods}

A prospective study of effect of stress on Central Serous Chorioretinopathy\& correlation with the type of leak on fundus fluorescein angiography(FFA) was done at a tertiary care Centre of the Armed Forces catering to serving personnel, ex-servicemen and their families from Jan 2015 to Dec 2015.

30 cases of freshly diagnosed Central Serous Chorioretinopathy were examined in detail. The patientsdemographic data was noted.A complete ophthalmological examination (Snellen visual acuity, slit lamp, 
fundoscopy) and specialized investigations OCT and FFA were done in all cases. The control group (30 patients) were taken from normal general population.

Within 6 weeks of onset of symptoms patients were asked a questionnaire based on Holmes and Rahe Stress Inventory. [Table 1].The scores for all 43 life events were totaled up.

\section{Results}

A total of 30 patients were evaluated. $93.3 \%(28)$ were males.( $\mathrm{P}<0.001$ chi-square test). The mean age was 38 years.10\% (3) patients had bilateral CSCR, $60 \%$ (18) had left eye and $30 \%$ (9) right eye involvement.The mean score on the Holmes Rahe Scale was 136.73. The maximum score was 235(individual was staying away from family, changed to a diff line of work, change in working hrs/ conditions, was a case of Duodenal ulcer had change in sleeping pattern and was due for retirement). The minimum score was 46 . The distribution of the various scores is shown in Graph $1.60 \%$ (18) patients had scores below 150, they had $30 \%$ chance of developing stress. $40 \%$ (12) patients had scores between 150-300, they had $50 \%$ chance of developing stress related disease. (Graph 2).

In the control group the mean score was 100.5. The maximum score was 202 and minimum was 44.70 $\%$ (21) patients had scores below 150, $30 \%$ (9) patients had scores between 150-300.(Graph 3).

60\%(18 patients) had inkblot leak, $26.6 \%$ (8) had multifocal leak and $13.3 \%$ (4) had smoke stack leak. $50 \%$ of the patients with multifocal leak had SRRS between 150- 299 compared to $36.36 \%$ among patients with single leak. (Graph 4)

\section{Discussion}

Psychological factors precipitate, and contribute to, the morbidity of many psychosomatic disorders. Wang et al ${ }^{[1]}$, Spahn et al ${ }^{[14]}$ and Conrad et $\mathrm{al}^{[15]}$ noted that patients with poor coping mechanisms when exposed to a stressful situation like divorce, critical illness developed CSCR. Gelber et $\mathrm{al}^{[17]}$ found that acute stressors preceded the onset of CSCR by a week. They also observed that removal of the stressor lead to improvement in the visual acuity within weeks.Conrad et $\mathrm{al}^{[15]}$, Gelber et $\mathrm{al}^{[17]}$ and Conrad et $\mathrm{al}^{[18]}$ found higher incidence of critical life events in patients of CSCR. Tatham et al ${ }^{[19]}$ noticed that treatment with beta blockers reduced sympathetic stress and may help in preventing recurrences. Sun et $\mathrm{al}^{[20]}$ found elevated levels of catecholamines, adrenaline and noradrenaline in patients of CSCR. Tiwari et $\mathrm{al}^{[21]}$ observed significantly increased sympathetic activity in patients of CSCR.

In our study compared to healthy controls CSCR patients showed a significantly higher degree of emotional stress. The stress scores as measured with the Holmes Rahe Scale was 136.73 in the CSCR group compared to the control group where it was 100.5.A larger number of patients had scores above 150 in the CSCR group (40\%) compared to the control group (30\%). Patients with multifocal leak had higher stress score compared to patients with single leak. (50\% had score above 150 vs $36.6 \%$ )

The limitations of this study is the small sample size. The Holmes Rahe Scale may not be ideal for Indian population.

\section{Conclusion}

CSCR is an idiopathic disease in which stress plays a role. Relaxation therapies \& stress managementprogrammes may help in preventing recurrences which is of paramount importance as $30-50 \%$ patients develop recurrences within one year ${ }^{[22]}$.

Table 1

\begin{tabular}{|l|l|}
\hline Life event & Life change units \\
\hline Death of a spouse & 100 \\
\hline Divorce & 73 \\
\hline Marital separation & 65 \\
\hline Imprisonment & 63 \\
\hline Death of a close family member & 63 \\
\hline Personal injury or illness & 53 \\
\hline Marriage & 50 \\
\hline Dismissal from work & 47 \\
\hline Marital reconciliation & 45 \\
\hline Retirement & 45 \\
\hline Change in health of family member & 44 \\
\hline
\end{tabular}




\begin{tabular}{|c|c|}
\hline Life event & Life change units \\
\hline Pregnancy & 40 \\
\hline Sexual difficulties & 39 \\
\hline Gain a new family member & 39 \\
\hline Business readjustment & 39 \\
\hline Change in financial state & 38 \\
\hline Death of a close friend & 37 \\
\hline Change to different line of work & 36 \\
\hline Change in frequency of arguments & 35 \\
\hline Major mortgage & 32 \\
\hline Foreclosure of mortgage or loan & 30 \\
\hline Change in responsibilities at work & 29 \\
\hline Child leaving home & 29 \\
\hline Trouble with in-laws & 29 \\
\hline Outstanding personal achievement & 28 \\
\hline Spouse starts or stops work & 26 \\
\hline Beginning or end school & 26 \\
\hline Change in living conditions & 25 \\
\hline Revision of personal habits & 24 \\
\hline Trouble with boss & 23 \\
\hline Change in working hours or conditions & 20 \\
\hline Change in residence & 20 \\
\hline Change in schools & 20 \\
\hline Change in recreation & 19 \\
\hline Change in church activities & 19 \\
\hline Change in social activities & 18 \\
\hline Minor mortgage or loan & 17 \\
\hline Change in sleeping habits & 16 \\
\hline Change in number of family reunions & 15 \\
\hline Change in eating habits & 15 \\
\hline Vacation & 13 \\
\hline Christmas & 12 \\
\hline Minor violation of law & 11 \\
\hline
\end{tabular}

Graph 1

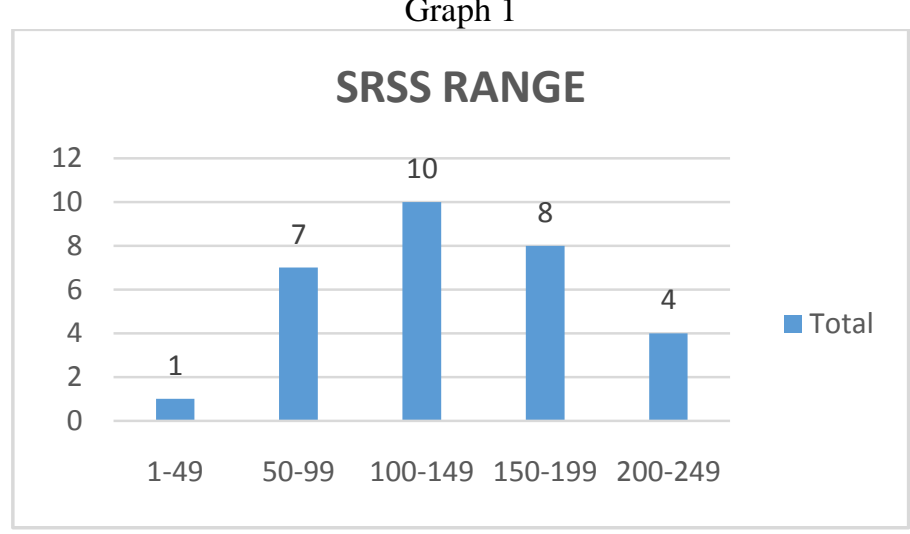


Graph 2

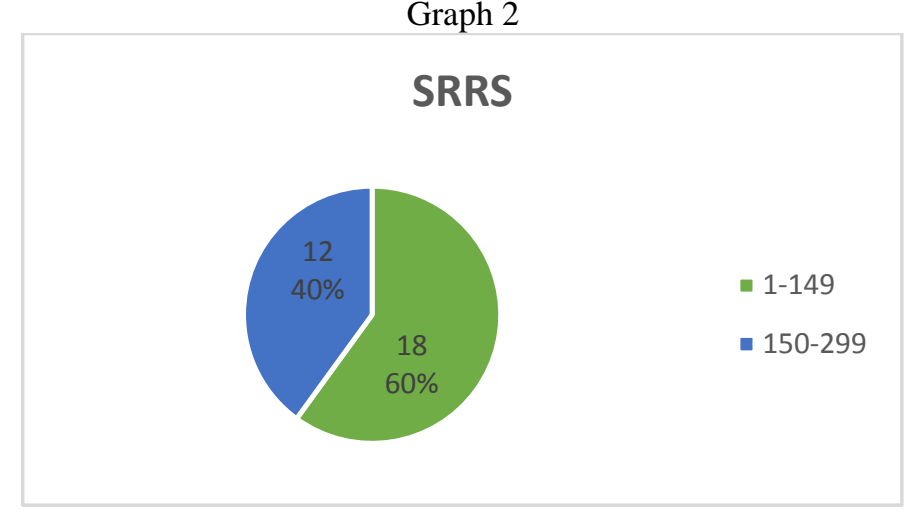

Graph 3

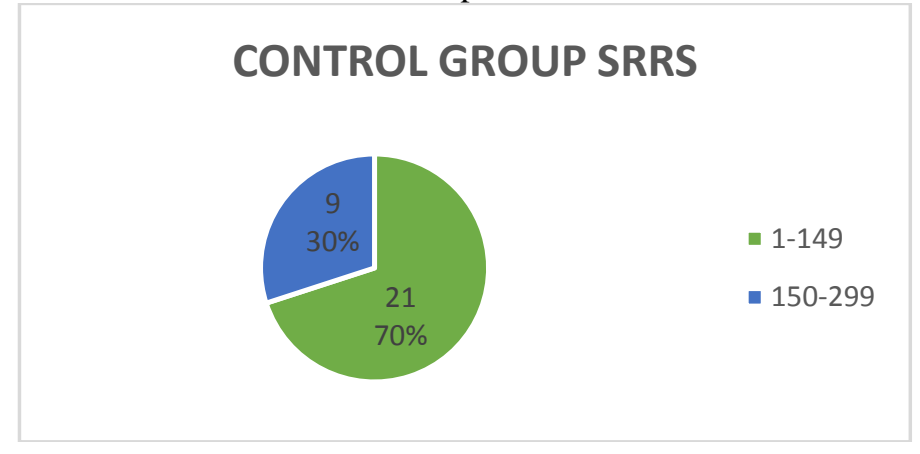

Graph 4

SRRS IN MULTIFOCAL LEAK \& SINGLE LEAKS

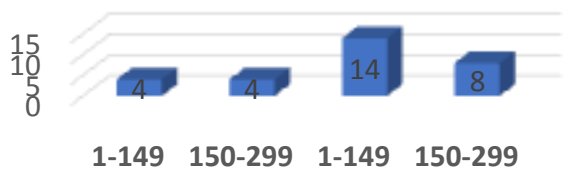

MULTIFOCAL LEAK SINGLE

\section{References}

[1]. Wang M, Munch IC, Hasler PW, Prunte C, Larsen M. Central serous chorioretinopathy. ActaOphthalmol 2008; 86: 126-45

[2]. Gass JD. Pathogenesis of disciform detachment of the neuroepithelium. Am J Ophthalmol 1967; 63 (Suppl.): 1-139.

[3]. Nair U, Ganekal S, Soman M, Nair K. Correlation of spectral domain optical coherence tomography findings in acute central serous chorioretinopathy with visual acuity. ClinOphthalmol. 2012;6: 1949-1954

[4]. Yanuzzi LA. Type-A behavior and central serous chorioretinopathy. Retina 1987, 7:111-30.

[5]. Wakakura M, Ishikawa S. Central serous chorioretinopathy complicating systemic corticosteroid treatment. Br J Ophthalomol 1984; 68: 329-331. 36

[6]. Polak BCP, Baarsma GS, Snyers B. Diffuse retinal pigment epitheliopathy complicating systemic corticosteroid treatment. Br J Ophthalomol 1995; 79: 922-925. 37.

[7]. Heimovici R, Gragoudas ES, Duker JS, Sjaarda RN, Eliott D. Central serous chorioretinopathy associated with inhaled or intranasal corticosteroids. Ophthalmology 1997; 104: 1653-1660. 38

[8]. Garg SP, Dada T, Talwar D, Biswas NR. Endogenous cortisol profile in patients with central serous chorioretinopathy. Br J Ophthalomol 1997; 81: 962-964. 39

[9]. Bouzas EA, Scott MH, Mastorakos G, Chrousos GP, KaiserKupfer MI. Central serous chorioretinopathy in edogenoushypercortisolism. Arch Ophthalmol 1993; 111: 1229-1233.

[10]. Kloos P, Laube I, Thoelen A. Obstructive sleep apnea in patients with central serous chorioretinopathy. Graefes Arch ClinExpOphthalmol 2008; 246: 1225-8. 48.

[11]. Jain AK, Kaines A, Schwartz S. Bilateral central serous chorioretinopathy resolving rapidly with treatment for obstructive sleep apnea. Graefes Arch ClinExpOphthalmol 2010; 248: 1037-9.

[12]. Spaide RF, Campeas L, Haas A, et al. Central serous chorioretinopathy in younger and older adults. Ophthalmology. 1996;103(12):2070-2079 


\section{Effect Of Stress On Central Serous Chorioretinopathy\& Correlation With Type Of Leak On}

[13]. Kitzmann AS, Pulido JS, Diehl NN, Hodge DO, Burke JP. The incidence of central serous chorioretinopathy in Olmsted County, Minnesota, 1980-2002. Ophthalmology. 2008; 115 (1):169-173.

[14]. Spahn C, Wiek J, Burger T. Operationalized psychodynamic diagnostics (OPD) in patients with central serous chorioretinopathy. PsychotherPsychosom Med Psychol 2004; 54: 52-7. 25.

[15]. Conrad R, Bodeewes I, Schilling G, Geiser F, Imbierowicz K, Liedtke R. Central serous chorioretinopathy and psychological stress. Ophthalmologe 2000; 97: 527-31.

[16]. Holmes TH, Rahe RH. The social readjustment rating scale. J 3. Psychosom Res 1967;11:213-8.

[17]. Gelber GS, Schatz H. Loss of vision due to central serous chorioretinopathy following psychological stress. Am J Psychiatry 1987; 144: $46-50$.

[18]. Conrad R,Weber NF,Lehnert M,Holz FG,Liedtke R and Eter N, "Alexithymia and emotional distress in patients with central serous chorioretinopathy," Psychosomatics, vol. 48, no. 6: 489-495,2007.

[19]. Tatham A, Macfarlane A. The use of propranolol to treat central serous chorioretinopathy: an evaluation by serial OCT. J OculPharmacolTher 2006; 22: 145-9.

[20]. Sun J, Tan J, Wang Z, Yang H, Zhu X, Li L. Effect of catecholamine on central serous chorioretinopathy. J HuazhongUnivSciTechnolog Med Sci 2003; 23: 313-6.

[21]. Tewari HK, Gadia R, Kumar D, Venkatesh P, Garg SP. Sympathetic-parasympathetic activity and reactivity in central serous chorioretinopathy: a case-control study. Invest Ophthalmol Vis Sci. 2006; 47:3474-3478.

[22]. Loo RH, Scott IU, Flynn HW Jr, et al. Factors associated with reduced visual acuity during longterm follow-up of patients with idiopathic central serous chorioretinopathy. Retina. 2002; 22:19- 24.

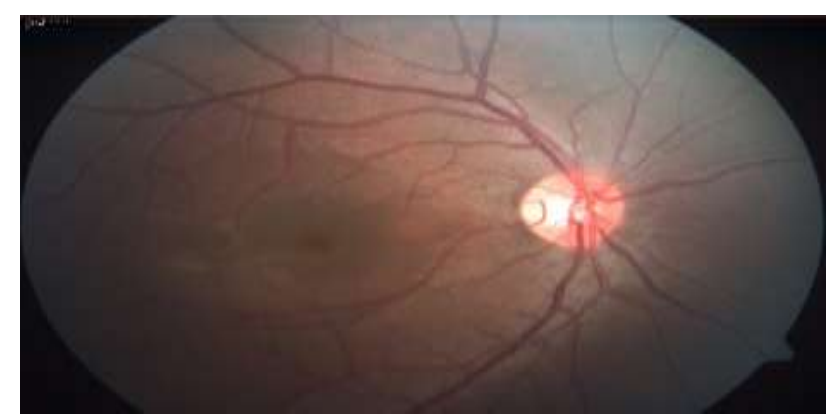

Figure 1- CSCR RE

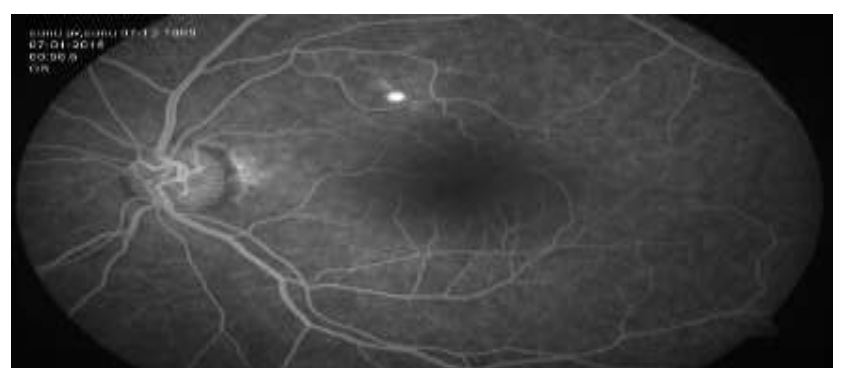

Figure 2- Inkblot leakage on FFA

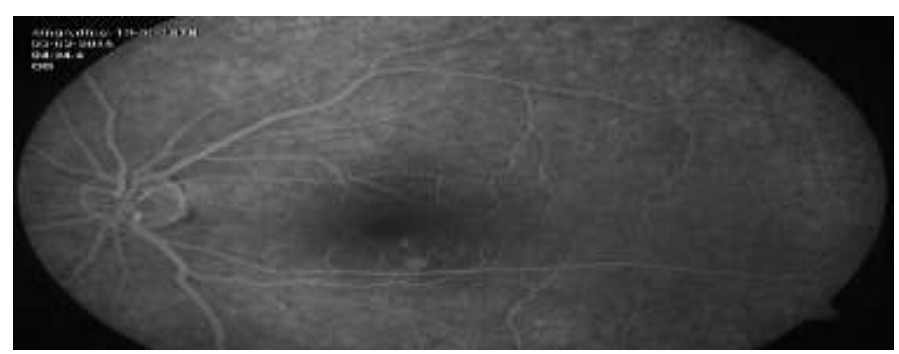

Figure 3- Multifocal leaks on FFA

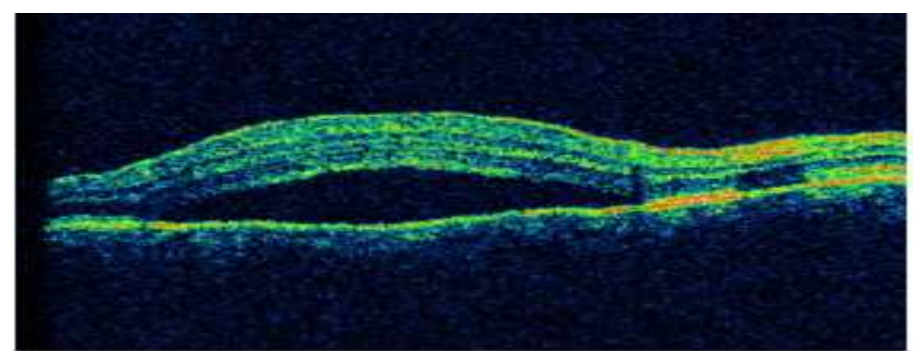

Figure 4- OCT Neurosensory detachment 